\title{
Playing (with) Democracy: A Review of Gamified Participation Approaches
}

\section{Sarah-Kristin Thiel, Michaela Reisinger, Kathrin Röderer, Peter Fröhlich}

AlT Austrian Institute of Technology, Vienna - \{sarah-kristin.thiel; michaela.reisinger; kathrin.roederer; peter.froehlich\}@ait.ac.at

Although a wide range of e-Participation platforms have become available, the level of public participation has remained low. In order to promote public participation, governments around the world as well as academia are currently exploring new ways to design participation methods that are more engaging to use. One of the applied strategies is to add game elements to eParticipation platforms, in order to evoke interest among previously less interested as well as to introduce additional motivations to increase engagement. This paper provides a review of gamification strategies in e-Participation platforms, and it seeks to provide an overview of the current state of the art of so-called gamified participation initiatives. Our results suggest that only a small amount of the reviewed projects employs gamification. Moreover, gamified participation initiatives currently seem to be mostly restricted to reward-based gamification, $a$ strategy which might only evoke short-term effects and decrease the quality of participation. Avenues to extend gamified participation are also outlined.

Keywords: e-Participation; gamified participation; review; gamification; civic games

Acknowledgment: This research was carried out within the project "Building pervasive Participation", which has received funding in context of the JPI Urban Europe financed by FFG, Tekes and Formas.

\section{Introduction}

Many people only know voting as a way to take part in public life. Lack of knowledge of other methods to engage is among the main reasons for the currently low level of public participation. Yet, even with widely known methods such as voting, active involvement of citizens is low in many countries (Brucher, 2003; Pahad, 2005). Being inactive in public issues can have undesireable consequences for both citizens and politicians: While the former restrain themselves in their opportunities to influence desicisions that affect their life directly, politicians loose the actual and democratic legitimation for their work as well as perspectives for future campaigns. 
Yet, considering recent movements around Stuttgart 21 or reactions to the "Brexit", a different picture emerges: People seem to be actively interested in politics, and they increasingly use Twitter, Facebook and other web-based services to share their opinions. To provide structured support for people in raising their voice, many governmental institutions have set up dedicated web-based participation platforms, which are subsumed under the umbrella term "eParticipation". Recently, such endeavors have also been adopted for mobile devices, resulting in a considerable number of mobile applications connected to municipalities or other official institutions (for a review, see Ertiö, 2013). The 2014 edition of the United Nations E-Government Survey points out that e-government - as an overarching concept - is a substantial pillar of effective, transparent, accountable and democratic institutions (Zichermann \& Cunningham, 2011). E-government has been recognized as a major building block for broad public participation in decision-making, enhancing access to information and removing barriers to public services.

A key challenge of e-Participation projects in the past few years has been to increase both the number of participating citizens and the intensiveness of public participation activities. Due to known barriers to political participation, such as a lack of interest, lack of time and low perceived political efficacy, this has turned out to be a challenging undertaking. Additionally, general openness and accessibility to technology remain considerable barriers to the adoption of eParticipation. Apart from these general, inherent constraints, the way e-Participation services are realized, in terms of aesthetics, usability and user experience, arguably plays a significant role in their adoption: A platform that is both easy and engaging to use will attract more users than one that requires a steep learning curve and is less engaging to use (Brown \& Pullar, 2012).

Human-Computer Interaction (HCI) has researched various strategies to ensure the high usability and an engaging user experience of digital tools. The research discipline also looks at how to design software that by itself (i.e., by design or content) influences users' behaviors and persuades them to interact with it in a certain way. One possible approach, which has a firm tradition in urban planning (Devisch et al, 2016), is to integrate game elements in participation systems - a strategy called gamification (Deterding et al., 2011). The amount of game characteristics adopted in public participation platforms differs and there are multiple types of gameful eParticipation platforms (Glenn, 2012, Walz \& Deterding, 2015).

This paper provides an overview of work conducted in the field of gamified participation and extends earlier work that described individual projects in this area (Thiel, 2016b). Using a selection of concepts from previous e-Participation evaluations, as well as definitions from game research, our review explores both participation and game-related aspects of gamified participation projects. For this paper, our analysis focuses on employed gamification strategies, describing which game elements have been used in which type of public participation initiatives. In contrast to previous literature reviews, our analysis is not limited to academic projects, but also looks at commercial and governmental e-Participation platforms.

In the following, we will first introduce and define the main concepts and terms used in this review, namely e-Participation and gamification. In a following section we outline the matrix employed for the review by introducing individual dimensions. The next section then describes how projects were selected and reviewed. This section also presents the findings of the review and 
their implications. After discussing the findings, the paper concludes with recommendations for future research.

\section{Defining Gamified Participation}

Per definition, e-government involves several disciplines such as social sciences, political sciences and computer science. These domains have differing conceptions of the same terms. Hence, we provide some clarification on the terms used in this paper and how we interpret them. In this chapter we discuss "public participation" and its multiple meanings as well as "gamification", providing further background on this concept. In the last section, we discuss why it is highly beneficial to combine the two research areas of public participation and gamification.

\subsection{Public Participation}

Participation is a very broad term that is used and interpreted differently across various domains. Participation can refer to merely providing citizens with information (e.g., about a planned or currently running process) as well as to more active forms of participation. Due to this ambiguity, several scholars have developed frameworks and models to structure existing forms of (e-) participation. The majority of frameworks define participation forms based on the level of influence citizens can exert. Arnstein's (1969) ladder of participation, which is probably the best known participation framework, consists of three stages: non-participation, tokenism and genuine participation. The degree of citizen empowerment in community planning and decision-making increases with every rung. In the last stage, citizens can actively and democratically exercise power. Typically frameworks are based on Arnstein's (1969) ladder and distinguish between three stages (or levels) of participation: information, consultation and cooperation.

The vast majority of existing e-Participation platforms allow only a moderate level of participation. Up until now governments operating those platforms have thus not tapped the full potential of augmenting participatory processes with the available technologies. As recent evaluations rightly critique, in most cases platforms only implement one-way communication between government and citizens (Thomas \& Streib, 2003). Instead of integrating interactive features (e.g., forums, instant messaging), most platforms serve as a tool to gather feedback from citizens (= citizen-sourcing). The belief that one's input will be considered and potentially realized, and thus has an impact on policies and decisions, has been listed as one of the main motivations for citizens to become active (Parent et al., 2005). Yet, offering highly responsive services translates to a high demand of resources (e.g., officials answering requests). Not every local administration is able or willing to meet such great expense. Taking challenges of effective and sustainable participation into account, Arnstein (1969) further cautioned against skipping a rung, as appropriate readiness is essential. Such readiness includes sufficient resources, corresponding policies and processes as well as the population's civic skills. In summary, a culture of participation ought to be present both in the population and in the governing institution in order to enable an efficient and sustainable participation process with discernible outcomes. 
Participation can also be described and categorized according to the involved stakeholders. On a broad level, this perspective differentiates between two notions of public participation: While citizens-to-citizen participation (C2C) is characterized by citizens discussing topics related to urban development or political issues amongst each other, citizen-to-government participation (C2G) involves the communication between citizens and an official authority (C2G). In the context of this research, we understand public participation as a synonym for political participation and thus refer to it as an interaction involving both citizens and authorities. Platforms that implement this form of engagement invite participants to take an active role in authoritative consideration and decision-making. For the purpose of this research, we do not differentiate between the intentions underlying the engagement.

\subsection{Gamification}

Gamification can be defined by specific actions, e.g., "adding game elements to non-game contexts" (Deterding et al., 2011). In fact, it is often compared to loyalty programs such as frequent flyer miles (Nicholson, 2012) because in both cases designers and developers aim to influence user behavior and "nudge" people towards desired actions or activities (Deterding et al., 2011). The main difference is that programs target customer loyalty by offering economic incentives (Hamari \& Koivisto, 2013) and that, while they are the most often applied elements and mechanics, gamification is more than adding points and badges on top of a system. The success of gamification relies on transforming non-recreational, tedious tasks, which are often driven by utilitarian motives, into enjoyable, self-purposeful and hence hedonistic activities (van der Heijden, 2004; Hamari and Koivisto, 2015). This ought to be achieved through invoking intrinsic motivations as the serious aspect of the system is masked by gameful design (Deterding et al., 2011; Hamari et al., 2015). In contrast to extrinsic motivation (i.e., being motivated by external goals and outcomes), intrinsic motivation is when people do things "for the sake of it" or because tasks align with their internal believes and values (Deci \& Ryan, 1985). The enjoyment arising from such activities is believed to be enough to encourage people towards certain behavior (Hamari \& Koivisto, 2015). In order for a gamified system to be successful in fostering or building motivation, it is important to find a suitable balance between utilitarian and hedonic benefits (Hamari and Koivisto, 2015). To this end, gamification includes other typical elements or characteristics such as narrative, feedback, clear goals (Hamari et al., 2014), as well as mechanics such as competition, mastery, scarcity and discovery (e.g., Chou, 2015).

Empirical studies reported mixed results of gamification: Increased engagement with a service, quality of the output as well as enjoyment of tasks (Itoko et al., 2014; Kawaijiri et al., 2014; Eickhoff et al., 2012) contrasts with negative results of gamifications strategies, especially pertaining to the use of rankings and leaderboards (cf. Preist et al., 2014). Leaderboards have been described as a double-edged sword which motivates certain users to continue their high engagement (i.e., those who are at the upper end of listings; Lee et al., 2013) while it demotivates others (i.e., novices and low-ranked participants). Based on their review of gamification in crowdsourcing systems, Morschheuser et al. (2016) note that the effect of leaderboards might be highly context dependent. Ipeirotis and Gabrilovich (2014) suggest the implementation of short-term leaderboards hence making it possible also for people who are new to the system to reach the top. Competition among 
participants can likewise lead to people stopping to use the system (Eveleigh et al., 2013). These findings support the notion that not every element will work the same way if applied in different contexts, hence also validating that "one [concept] fits all" does not apply to gamification (Devisch et al., 2016; Morschheuser et al., 2016). The success of a gamification strategy depends on a suitable implementation of the individual game characteristics in the respective context (Deterding et al., 2011). To properly "situate" game elements, it is necessary to first investigate the exact effects of the respective game elements in various contexts. It has yet to be shown, especially via empirical results, a) which implementations work best in which contexts (Morschheuser et al, 2016), b) which psychological effects mediate gamification effects, and c) whether the reported affordances have actually been caused by game elements (Hamari \& Koivisto, 2015). This paper prepares for such investigations by providing an overview of the different contexts and forms of gamified participation. Despite being limited to the amount of evaluated academic, commercial and governmental projects, the current practice of applying game elements to e-Participation systems is introduced as well as gaps and opportunities for future work are identified.

\subsection{Gamified Participation}

The idea of interlinking games with public participation is not entirely new. In the 1980s, urban planners in the United States used simulation games to facilitate the visualization of complex planning structures and processes (Mayer, 2009; Taylor, 1971). Building on the success in terms of positive outcomes and fun aspects, these planning games were transformed into commercial video games such as Metropolis (Duke, 2011) or SimCity (Devisch, 2008).

Games can benefit participatory processes by providing contexts for engaging as well as educating stakeholders. Game-like contexts enable stakeholders to explore, plan, test and train in a safe environment (Mayer, 2009), typically allowing users to not fear (legal) consequences and other real world implications. Abiding by a given set of rules and making use of the simulated environment, citizens as well as authorities can experiment with options and thus discover new solutions. In this context, Mayer described simulation gaming as "a rational and analytical method for [...] policy making and planning". Moreover, both games and gamification services (Hamari \& Koivisto, 2015) can include social features. Such features allow for empathy and community building (Flanagan, 2009), which align with the goals and outcomes of deliberative democracy (Lerner, 2014). In processes labeled as collective reflection (Gordon \& Baldwin-Philippi, 2014a), users learn from other users' proposals and views, gaining a broader understanding of challenges and opportunities at hand. Gameful design therefore enables civic learning, the generation of new solutions and the improvement of public decision quality (Chakraborty, 2011). Civic learning is a factor so far missing in traditional participation forms such as town hall meetings, but has been pointed out as important for ensuring sustainable public participation (Gordon \& BaldwinPhilippi, 2014a).

The advantages of games include that they are "extremely flexible and adaptable" (Mayer, 2009). As such, they can be utilized in a variety of decision-making stages and for various purposes (e.g., urban planning, public health policies). Furthermore, simulation games are particularly well suited for deliberation processes, because as mediums they allow far greater expression than rigid 
calculations. Expression has been described as a mechanism that taps into the creative powers of players and the creation of an identity (Laureyssens et al., 2014).

\section{Defining the Review Matrix}

While the number of frameworks for evaluating e-Participation was quite low seven years ago (Aichholzer \& Westholm, 2009), it has been steadily increasing. Yet, in most cases, these categorizations do not evaluate the impact of initiatives and hence do not provide insights about their performance or effectiveness (Rowe \& Gammack, 2004; Nam, 2011). A notable exception is Toots et al. (2016), who assessed three e-Participation platforms in Estonia on the basis of user take-up and implemented ideas that evolved from discussions within these platforms.

In 2012, Glenn (2012) provided a first categorization of gameful engagement systems, similar to our present paper. However, she focused on applications that enabled budget-planning and only distinguished between toys and single- or multi-player games. Her resulting framework identified multiplayer toys as an unexplored area that would be worth investigating. In the gamification domain, there is a dearth of structural reviews with a few notable exceptions (Hamari \& Koivisto, 2015; Hamari, Koivisto, \& Sarsa, 2014). Mayer's (2009) detailed analysis of the emergence of urban planning and policy games over a course of 40 years is one of the rare reviews of gamified participation projects. While he lists and sketches a large number of gamified participation projects and sorts them in accordance to their type (i.e., simulation game, serious game), his analysis lacks a more systematic categorization or framework to structure the identified projects. While one part of our categorization is similar to existing categorizations of e-Participation initiatives, we go beyond standard frameworks by including also aspects from games research and Human-Computer interaction, increasing its interdisciplinary breadth.

This section introduces the framework we developed to characterize the reviewed eParticipation platforms. In the following, we elaborate on the framework's dimensions and their respective values (highlighted in italics). As this paper reviews prior works at the intersection of eParticipation and gamification, the framework used to characterize individual projects consists of two axes: one that describes participation-related aspects of the system and another that looks at the system from a game-oriented perspective. The framework further outlines the conditions under which the respective e-Participation system was (or is) operated. Hence, we included a third, the so-called general axis, in our review matrix.

As such, this paper does not only introduce a new framework of evaluating e-Participation initiatives, but additionally serves as a structural guideline for categorizing the use of game-related components in e-Participation platforms. Our review matrix is a first approach to structure practical work conducted in the domain of gamified participation systematically rather than offering a complete or final categorization. As this review should be used by a diverse range of actors including academics from various disciplines as well as practitioners and designers, we aimed at creating a universally understandable, intelligible framework. In order to do so, we tried to avoid overly technical terms. 


\subsection{E-Participation Aspects}

The first axis of our review matrix describes the participatory aspects implemented in the respective project. As we anticipate that some of the dimensions within our framework are selfexplanatory, we only introduce those that are either more complex or that include terms or concepts we interpreted differently from the definition or common use in literature.

Table 1: The Participation-Related Dimensions (First Axis)

\begin{tabular}{lll}
\hline Dimension & Values & Source \\
Data collection & Citizen science, Citizen-sensing, Citizen- & Based on multiple \\
& $\begin{array}{l}\text { sourcing, Public deliberation, Participatory } \\
\text { budgeting, none }\end{array}$ & concepts \\
Stage in decision- & Agenda setting, Option analysis, Draft policy, \\
making & Implementation, Monitoring & (Macintosh, 2014) \\
Type of engagement & $\begin{array}{l}\text { Tell, Ask, Discuss, Decide, DIY, Vote/Sign, } \\
\text { (Civic) Learning }\end{array}$ & (Rucker, 2015) \\
Involved stakeholders & $\begin{array}{l}\text { C2C (citizen-to-citizen), C2G (citizen-to- } \\
\text { government), G2G (government-to- }\end{array}$ & / \\
government) & Based on (Rowe \\
Communication form & One-way, Limited two-way, Two-way, & \& Frewer, 2005) \\
Dopic scope & Dialogue & $/$ \\
Spatial reach & Yes, No & Specific, Local, National, International \\
Restricted access & Yes, No & /
\end{tabular}

\subsubsection{Data Collection}

The dimension data collection describes the conceptual approach that shapes the participatory process reproduced in an e-Participation platform. The question is which stakeholders frame the participatory process. In that sense, the framing stakeholders are usually also the primary recipients of the resulting information (Reddy et al., 2009). Aiming to be more concrete than the common dichotomy of top-down and bottom-up, we employ a categorization that is based on established terms for various forms of participation. These terms not only state, who is collecting data, but also indicate both the type of data collected and the purpose of this data collection. For this dimension, we distinguish between: citizen science, citizen-sensing, citizen-sourcing, public deliberation and participatory budgeting. Strictly speaking, citizen science does not define public participation as we have done it for the scope of this categorization. Having been defined as "a 
collaborative process where volunteers work with professional scientists to study real world problems [3]", citizen science does not (neccessarily) concern urban topics that involve an official institution such as a city administration. Thus, citizen science is an instrument for data collection rather than for communication.

The second form is citizen-sensing (also called participatory sensing; Burke et al., 2006) where input from citizens is gathered through different sorts of mobile (not fixed) sensors (e.g., accelerometer, GPS, camera; Ueyama et al., 2014). Citizen-sensing stands in contrast to citizensourcing where citizens can control what data (text-based or audio in most cases) they provide. In this sense, citizen-sensing can be described as a format where citizens are passive in the data collection whereas in citizen-sourcing citizens are actively creating input. These forms, however, have in common that representatives or city officials are the ones determining the scope and context of input (i.e., which topics are addressed in the participatory process), while citizens only respond regarding specified topics. This fact marks both these types of e-Participation as top-down approaches. A more open form of public participation is public deliberation. Here, citizens can also propose topics and start discussions about issues that might not have been on an official agenda. The OECD (2001) published a list of six guiding principles for engaging citizens in policy making through deliberative processes. This list includes key aspects for public deliberation as the need to facilitate group discussions and maximize information sharing. By meeting these requirements, public deliberation can "reduce friction and competition between interests" (Torres, 2007). The fifth category, participatory budgeting, describes the purpose of the participatory process rather and how data is collected. Participatory budgeting refers to providing citizens the opportunity to codecide how the city's budget is spent. Similar to citizen-sensing and citizen-sourcing, the context within participatory budgeting projects is pre-defined, as the government asks citizens how and on what to spend which amount of a budget. There are also participation platforms that do not collect any type of data. This particularly applies to projects falling under the category of games and playful design as described in 3.2.2 (Game type).

\subsubsection{Stage of Decision-Making}

Another approach to describe participation and the amount of influence citizens can have on policies and plans is by looking at the subject's stage of decision-making in the participatory process. A general rule claims that the more mature something is in the process, the less influence citizens can take. For this dimension, we adopted Macintosh's (2004) categorization of various stages of decision-making: agenda setting, option analysis, draft policy, implementation and monitoring. In the first stage, agenda setting, the objective of participatory processes is to crowdsource topics to be addressed in the upcoming policy cycle. Here, the focus is less on deciding and deliberation, but more on getting a better understanding of which topics are important to citizens and should be addressed in the near future. In option analysis, the agenda is already set but the available options are not clear yet or have not been sufficiently defined so far. Here, a participatory process seeks for deliberation on possible options. In the stage of drafting a policy, the aim lies in assessing and defining key aspects that need to be considered for the implementation of a policy or plan. Participatory processes taking place during implementation follow the objective of informing and potentially also involving citizens in the execution of an agenda or plan. Finally, in the monitoring 
stage, the current state of a situation or context ought to be assessed either by enabling citizens to critically reflect on current practices or by asking specific questions about the acceptance of certain implementations.

\subsubsection{Communication Form}

While the dimension involved stakeholders specifies the number and type of stakeholders involved in the participatory process, and data collection refers to their roles in that process, communication form describes the possible degree of interactivity in the platform from an information science perspective. Following and extending Rowe and Frewer's (2005) categorization of the flow of information, we distinguish four forms of communication: one-way; limited two-way, two-way and dialogue. This dimension also touches on the responsiveness (i.e., degree of feedback provision) of the participation platform. Under one-way participation platforms, we subsume systems that do not provide any kind of feedback to citizens' input, meaning that there is either no possibility (i.e., feature) to respond or no intent to have reported issues and ideas commented. Limited two-way communication refers to the possibility of receiving feedback, which is limited by either not being specific to individual entries (e.g., "Thanks for your input. We will forward your input to the responsible department.") or not being extensive enough to be meaningful for the overall process (e.g., "We checked your input and concluded that this is not possible."). In general, platforms implementing a limited two-way communication do not allow for following up on feedback from authorities. Platforms allowing for a two-way communication on the other hand enable an exchange of information in both directions, both officials and citizens can respond to each other's comments. The difference to dialogue is that in a two-way communication channel there is a significant delay between responses. The communication within a dialogue setting could be compared to a (somewhat slower) version of instant messaging between authorities and the public.

\subsubsection{Type of Engagement}

As outlined in our terminology section, there are several models used to describe the type of participant engagement that can be achieved with a participation method or tool. The majority of these frameworks distinguish between three levels of participation: information, consultation and cooperation (Caddy \& Vergez, 2001). In most cases, these three levels are already a simplification of the sum of democratic acts that are reproduced within a particular system. In an attempt to better describe the maturity of such systems as well as reflect the complexity of (public) participation, some scholars expanded this 3-phase model and included sub-categories (Tambouris et al., 2007). Due to this high level of complexity and following our principle of understandability, we chose the comprehensive model by Rucker (2015), consisting of four levels: Tell, Ask, Discuss, and Decide. Apart from the suggestive terminology choice, the framework comes with the advantage of additionally providing information about the type of communication being possible in the participation system. Moreover, the terminology hints at the level of involvement and empowerment citizens are given. In Telling forms of engagement, government officials provide citizens with information regarding various aspects of planning, pending decisions and outcomes. Here, citizens' options for response or any form of interaction are heavily limited. Thus, the public 
takes on the role of "passive listener" (Rucker, 2015). In that, Telling very much resembles the information level of participation. To some extent, Asking is the reverse of Telling as officials here do not provide information but request feedback and input (i.e., ideas, visions). Background information as well as comments from officials are provided only rarely and often rudimentally. Both Telling and Asking can be described as top-down approaches that are limited to a one-way exchange of information. Discussing introduces a two-way communication channel and is characterized as an exchange of information between public and officials participants. One of the main objectives of Discussing is collective learning, which allows for a more nuanced and comprehensive understandings of issues. In Discussing forms of engagement both the public and officials become active and are challenged to take other people's perspectives and priorities into account. Finally, in Deciding, citizens are empowered to make decisions. While not yet reaching the level of a Do-it-yourself government, forms implementing a Decide type of engagement allow for collaborative decision-making. By enabling a two-way dialogue between the public and officials, Deciding engagement forms well-informed and hence defensible foundations for decisions and agenda-setting.

As Rucker's framework does not cover all types of engagement realized in current eParticipation platforms, we extended her framework by three categories: Vote, Do-it-yourself (DIY), and Civic Learning. Vote could be seen as a spin-off from Decide, as by voting people essentially decide on a matter - but on a single occasion. A (democratic) decision only can be derived when taking all votes together. In e-Participation platforms implementing a Deciding level, citizens are empowered to jointly define, deliberate, and eventually select an option to be implemented. In contrast to Voting, these decisions are only rarely binding. For the purposes of categorization, we employ the term of DIY government as a type of engagement where citizens take the lead of organizing or independently organize participation initiatives and try to solve issues on their own. The third additional category is civic education. As outlined before, games are commonly employed to train new personnel such as future urban planners and to broaden the understanding of the public regarding urban complexities including stakeholders' roles, interdependencies and the distribution of responsibilities. In participation platforms classifying as implementing a civic education type of engagement, the main objective is not to collect input from citizens or other stakeholders or in that sense involve them in decision-making, but rather serve the aspiration to receive "better qualified" proposals and requests (Bohøj et al., 2011) by preparing the public for future participatory processes.

\subsubsection{Topic Scope, Spatial Reach and Restricted Access}

The dimension "topic scope" indicates whether the e-Participation platform addresses a specified topic (e.g., transport, energy, tourism) or is open to input regarding all kinds of topics. When marked as open to topics, it could also mean that in its current implementation the platform focuses on one topic but can theoretically be used for any type of topic.

"Spatial reach" refers to whether the discussions in the platform address issues and ideas only within a certain spatial boundary. For instance, a platform that is merely concerned with situations 
in a certain city would be classified as local; a nationally orientated platform on the other hand takes in issues and proposals of a whole country.

While spatial reach refers to the subject of discussions and input, the dimension "restricted access" refers to the origin of people allowed to participate. Some platforms enable participants from all over the world to join discussions, whereas others implement a kind of filter or registration process, allowing only local citizens to create input.

\subsection{Game-Relevant Aspects}

This section describes the dimension that were used to categorize the reviewed e-Participation platforms according to their game-relevant aspects.

Table 2: The Game-Related Dimensions (Second Axis)

\begin{tabular}{lll}
\hline Dimension & Values & Source \\
Game type & $\begin{array}{l}\text { Game, gameful design (gamification), playful } \\
\text { design, toy }\end{array}$ & $\begin{array}{l}\text { Deterding et al., } \\
\text { Game genre }\end{array}$ \\
& $\begin{array}{l}\text { Action, Adventure, Role-play, Simulation, Puzzle, } \\
\text { Strategy, Sport, n.a. }\end{array}$ & $/$ \\
Game platform & Video game, Card game, Board game, Street game, & $/$ \\
Game elements & Arcade game, Pervasive game, Public game, n.a. & \\
Required players & Multiplayer, single-player 4 & Thiel, 2016b \\
\hline
\end{tabular}

\subsubsection{Game Type}

One of the objectives of the present research is to reveal gaps and find opportunities concerning the creation of more enjoyable and engaging participation experiences. As the majority of projects at the intersection of e-Participation and games have been entire games, we distinguish the reviewed platforms based on the type of game they represent. The selection of "game types" used in our categorization is based on a commonly used scheme to illustrate the differences between game and gamification. This scheme, often depicted as coordination system (cf. Deterding et al, 2011), sorts the four main game-related types, namely (serious) games, gameful design (which includes gamification), playful design and toys, into quadrants. In the resulting four-squared scheme, the $y$-axis refers to the dichotomy between game and play. The x-axis refers to the extent to which a system resembles a game, denoted as the amount of game-related concepts (i.e., elements, mechanics) included. According to the scheme, games focus on a rule-bound, goaloriented play and include a fair amount of game characteristics. They stand in contrast to playful design, which creates spaces for open, free-form play and only employs a small selection of game 
characteristics. Almost exclusively focusing on games and leaving little space for play is gameful design (= gamification), where the number of game characteristics employed varies. Toys on the other hand work with more game characteristics but allow for open play. Summarizing Abt's (1970) remarks on what constitutes a game, Poplin (2012) describes games as "a context with rules among adversaries trying to win objectives". Across definitions of games, two aspects coincide: rules and goals. Accordingly, we classified an application that is regulated by rules or specifies goals as a game. Being a sub form of games, serious games follow similar structures. The main delimiter here is the primary goal of those games: While typical games are meant for entertaining their users, serious games aim at educating their users (Michael \& Chen, 2005). This education can take various forms and range from merely informing users about facts and circumstances to training users for specific purposes. Another category used in the dimension game type is gameful design/gamification. Whereas this concept also pursues outcomes, gamification has the objective of the designer or operator in interest. Instead of (exclusively) focusing on entertainment, gamification uses game-related elements to encourage a desired type of behavior (Deterding et al, 2011), but also to make tedious tasks more enjoyable (Eveleigh et al., 2013). Applied to the participation context, the goal of applying game elements to platforms is foremost to foster participation (see section Introducing Gamification).

\subsubsection{Game Genre}

The topic and definition of "game genres" is a highly controversial topic within the games research community. The plethora of definitions to be found in both literature and online forums is heterogeneous and contradictory. In addition, the granularity of definitions for game genres differs; while some make an effort to keep the list of genres concise (Newman, 2004), others list over forty different genres (Wolf, 2001). In fact, publications attempting to structure games and applications with a gameful design into categories usually are discussions on the potential theoretical grounding for genre definitions rather than definitions (Clearwater, 2011). Having reviewed a large number of game genre definitions and frameworks, Clearwater (2011) concludes that subject matter and intended use (e.g., education, marketing) are the defining elements of a genre and its various subcategories. As our selection of projects was already filtered based on the intended use (here public participation), our list of game genres reflects the game aspect incorporated in the respective e-Participation platforms. Following our intention to provide a comprehensible categorization, we opted for a shorter list of game genres: action, adventure, roleplaying, puzzle, simulation, strategy, sports. Notably, this dimension predominantly makes sense for games and less for "serious" applications. For the latter, we included the category of an initiative belonging to no specific game genre.

\subsubsection{Game Platform}

Whalen notes that an often-overlooked aspect in scholarly discussions is the categorization by platform, which can significantly influence the gaming/playing experience (Whalen, 2003). Therefore, our categorization includes the dimension "game platform", which comprises the following categories: video-game, card game, board game, street game, arcade, pervasive game and public game. Similar to the genre dimension, this dimension has an additional "not applicable" category. 
While card, board and arcade games are arguably clear categories, the others are not. Video-games include all games or applications that run on any type of personal device or computer with a display (e.g., Xbox, Nintendo, laptop, smartphone) and are entirely contained within that device (e.g., do not augment or interact with the outside world). Street games refer to games that are played out in the open (e.g., in the streets) and usually do not require any type of technology (e.g., Buck buck). Pervasive games are a type of street game that require some sort of - mostly mobile technology as digital elements augment the gameplay (e.g., represent the game world as in PokémonGo). Finally, public games are games or playful interactions that are mediated by a public display or another tangible interface technology (e.g., table tops).

\subsubsection{Game Elements}

When investigating the effects of introducing game elements to e-Participation platforms it is necessary to define these game elements. A plethora of frameworks cataloging game elements can be found in literature (e.g., Chou, 2005; Hunicke et al., 2014). Deterding et al. (2011) describe game elements as "elements that are found in most (but not necessarily all) games, readily associated with games, and found to play a significant role in gameplay". Other definitions rarely use the same terminology or abstraction level: While some focus on visible interface elements, others focus on underlying concepts and mechanics. In our literature review, we did not come across one topology that covered all aspects found in the categorization presented here. As it is the objective of this paper to give an overview of gamified participation tools and not to propose a new framework for game elements, we based this dimension on a previous review of gamified participation tools (Thiel, 2016b). Table 4 provides an overview and description of game elements identified in the following review.

Table 3: Overview of Game Elements Found in the Review of Gamified Participation Tools

$\begin{array}{lll}\text { Classifier } & \text { Game elements } & \text { Description } \\ \text { Achievement } & \text { e.g., badges } & \begin{array}{l}\text { A mechanism to show the user his or her } \\ \text { progress and achievements within the } \\ \text { system }\end{array} \\ \text { Points } & \begin{array}{l}\text { Users can earn virtual points that in some } \\ \text { cases can be used to redeem physical } \\ \text { artefacts. }\end{array} \\ \text { e.g., levels } & \begin{array}{l}\text { In contrast to points in leaderboards, the } \\ \text { underlying mechanic that aims to motivate is } \\ \text { the strive for recognition by others and } \\ \text { findings one's place in a community. }\end{array}\end{array}$




\begin{tabular}{|c|c|c|}
\hline Expression & $\begin{array}{l}\text { e.g., spaces for } \\
\text { open creativity }\end{array}$ & $\begin{array}{l}\text { Where used, these spaces for open } \\
\text { creativity/creation are usually the main } \\
\text { component of the system. }\end{array}$ \\
\hline Feedback & e.g., notifications & $\begin{array}{l}\text { The system provides the user with } \\
\text { additional information, hints or gives } \\
\text { encouraging statements. }\end{array}$ \\
\hline Personalization & $\begin{array}{l}\text { e.g., profiles, } \\
\text { avatars }\end{array}$ & $\begin{array}{l}\text { The system offers a space that contains } \\
\text { information about the specific user or can be } \\
\text { modified by the user. }\end{array}$ \\
\hline Challenge & $\begin{array}{l}\text { e.g., missions, } \\
\text { quests }\end{array}$ & $\begin{array}{l}\text { The system or other users ask the user to } \\
\text { perform a certain activity under predefined } \\
\text { conditions. }\end{array}$ \\
\hline Competition & $\begin{array}{l}\text { e.g., } \\
\text { leaderboards, } \\
\text { highscore lists }\end{array}$ & $\begin{array}{l}\text { Competition does not necessarily connect to } \\
\text { rivalry, but can also be neutral comparison. }\end{array}$ \\
\hline $\begin{array}{l}\text { Time } \\
\text { constraint }\end{array}$ & $\begin{array}{l}\text { e.g., due dates, } \\
\text { countdowns }\end{array}$ & $\begin{array}{l}\text { Users are given a certain amount of time in } \\
\text { which they ought to perform or complete a } \\
\text { specific activity. }\end{array}$ \\
\hline
\end{tabular}

\subsection{General Aspects}

As a final step in characterizing e-Participation platforms that make use of game-related components, we structured relevant projects into categories based on rather elementary criteria, in this case, initiator of the platform or project, "technology base" and "time limit". The first dimension allows us to distinguish between projects that had been initiated within an academic setting (i.e., research projects), have a commercial focus or were setup up within a governmental frame. Moreover, it reviews the type of technology employed: With e-Participation defined as the utilization of information and communication technology (Macintosh, 2004b), the values for the "technology base" dimension include (1) web-based (i.e., the platform is accessible through a web browser), (2) mobile (i.e., the platform is a mobile application), (3) public screen (i.e., participation is only possible via a large display located at a publicly accessible space), (4) pop-up (i.e., a dedicated infrastructure such as a booth equipped with technology like monitors and sensors installed at a publicly accessible space) and (5) wearable (e.g., a smart watch used for informing participants). Some e-Participation initiatives make use of several technologies at once; those we categorized as being a (6) hybrid solutions. In order to give some sort of indication about the duration of underlying participation process, we included the time limit of the initiative. However, sometimes 
no dedicated time frame was indicated or could be found. In these cases, we checked whether the initiative seemed to still be "alive", i.e. data input was still possible or there was a certain amount of activity in the last months.

Table 4: The General Dimension of the Framework (Third Axis)

\begin{tabular}{ll}
\hline Dimension & Values \\
Initiator & Academic, Commercial, Governmental, Other \\
Technology base & $\begin{array}{l}\text { Web-based, mobile, public screen, pop-up, } \\
\text { wearable }\end{array}$ \\
Time limit & No, $<$ specified duration $>$ \\
\hline
\end{tabular}

\section{Systematic Review}

This section presents the actual review of recent e-Participation platforms that incorporate gamerelated elements and aspects. The unit of analysis for this review are all sorts of systems that implement a form of participatory process in which citizens can take part. These could be mobile applications, web platforms, applications running on public screens or digitally enriched artefacts. Before describing the individual projects and systems, we will elaborate on the selection of the reviewed systems.

\subsection{Methodology}

In order to identify existing gamified e-Participation platforms, we conducted a systematic search that encompassed two search strategies. The first strategy looked at academic projects. For this we scraped common academic databases such as Scopus or Google Scholar, by using combinations of the following search terms: "game element", "gamification", "e-Participation", "engagement" and "public participation". Hits to these searches were considered when the source either described an actual (i.e., implemented) or proposed software application that had been specifically designed for the use in public participation processes. These tools further had to be published in scientific journals, books or conference proceedings and be publicly accessible. Leveraging from the related work section in these publications, projects cited in academic publications were also included in our review. These also fed into our second strategy, which we employed to find commercial or governmental projects. As both commercial and governmental projects do not usually advertise the gamefulness of their application, we decided to further look for "normal" (= non-gamified) eParticipation platforms. In order to find those we conducted Google searches using similar search terms as for the academic projects. Depending on an online search engine brought the advantage of discovering predominantly ongoing or recent projects, instead of outdated tools.

For the selection of relevant applications we refer back to our interpretation of the term "public participation". As such, for an application to be included in this review it would need to engage at 
least two stakeholders, ideally citizens and an authority. While citizen science is closely related to public participation and has many parallels such as the objective to involve society, it fails one of the main criteria of public participation, namely serving a purpose that is related to civic topics. Under civic topics we understand all circumstances that a government or an official institution can influence. Going back to the definitions of citizen science, the objective of this approach is to "solve real world problems" (Cohn, 2008). Civic topics surely classify as such; however, as citizens work with "professional scientists" (Cohn, 2008), these problems hardly fall under the responsibility of city administrations. Bowser et al. (2014) make this difference even more clear when saying that citizen science supports public participation in scientific research.

A second requirement determining the relevance for this review, is that the system needed to include at least one game-related aspect in order to classify as being gamified. As gamified participation is still a novel concept and especially as research in this domain is in its infancy, there are yet only few published works that would fulfill all our selection criteria. Therefore, we chose to also include applications belonging to the related domain of citizen science as well as applications where the main purpose is to educate users (i.e., citizens, future urban planners) pertaining procedures, roles and complexities that relate to public topics. Not having included related keywords, our initial sample had only included two citizen science projects.

It is important to note that the sources of our review and hence its results are based on differing levels of detail. Some of the websites and publications described the project very precisely or even allowed to (play-)test the projects. Regarding those cases, we are quite confident that our categorizations are accurate. Other projects offered us very little material to work with (i.e., a few paragraphs briefly outlining the project), making it sometimes difficult to pick the right category within dimensions. Another challenging aspect was that some descriptions did not cover all our dimensions. For instance in several proposed applications it was not mentioned what would happen to the collected data. To ensure high quality and validity of the review, such projects were marked and coded by a second or - where necessary - a third researcher. When this re-coding resulted in conflicts, the respective dimensions were discussed until a decision was reached.

At the end of the search process, we had identified 130 projects. These projects were fed into a list and then analyzed according to the previously described matrix of dimensions. During the categorization of the identified projects, the review matrix was adapted and extended (i.e., missing values added to dimensions), whenever it became necessary. For instance for the dimension data collection we came to realize that not every platform that enables citizens to engage necessarily collects any kind of data. Some games or platforms with playful elements predominantly serve the purpose of civic education, meaning it is anticipated that citizens learn something about underlying processes, structures or roles of stakeholders when "playing" or "using" the system; however, during "play" no data is logged.

\subsection{Results}

In this section we report the results of our literature review. While we do not claim that this review is extensive or complete, our goal is to provide an overview of what has been done in the last years 
regarding the incorporation of game-related components and mechanics in e-Participation platforms in order to increase citizen' involvement in political decision-making.

A first and early finding is that not every project that claims to allow for public participation keeps true to this promise. From the 130 reviewed projects seven were excluded as they had no apparent or underlying connection to a participation process. While still falling under our definition of public participation and hence classifying for this review, in nine projects the participation aspect was hidden. For instance, games such as SustHouse (Sust, n.d.) aim to improve civic education by allowing players to construct and manage their own towns, hence broadening citizens' understanding of urban complexities and preparing them for future participation processes.

A second early revelation concerns the low number $(6 / 92 ; 7 \%)$ of projects that did not use any kind of technology. Although we had originally been scouting for digitally mediated participation platforms, the selection of search terms (see previous section) would have allowed the identification of any game-related participation platforms irrespective of their technology base. Once again, this illustrates that all parties, irrespective of being commercial or academic, have adapted to the paradigm shift of using information and communication technologies for participation. Examples for projects that do not use any technology are the card-game @Stake (Gordon et al., 2016) and the serious board game ParticiPécs (Tóth \& Poplin, 2014). As this review focuses on e-Participation, we excluded projects not using any technology for the following analysis.

\subsubsection{Social Participation Forums and Competitive Participation Platforms}

Another finding was that about $50 \%$ of the reviewed projects could be categorized as being gamified. Surely, this percentage highly depends on how game elements are defined as this determines the span of features, components and concepts classifying as game-related. Aiming to create clear snapshots of the game/gamification strategies in participation systems we also included items in our game elements dimension that are not unique but are commonly used in games (e.g., feedback, progress). A question that arouse during the classification was whether there is a threshold of how many game-related elements a system needed to order to be considered gamified. There surely is no upper bound; conversely, we argue that there should be a threshold defining how many elements, which are unique to games, need to be incorporated in a "serious" system in order to count as gamification. This especially became pertinent to us as several projects only scored on one game element (e.g., Next Stop Design (Brabham, 2009): challenge; Activism (n.d.): progress). Other systems rather resembled social networking platforms than classical gamified tools (i.e. working with achievement systems and the competition mechanic). A comparison with social networks seemed appropriate as many participation platforms allow users to vote or "like" other users' content and include commenting functions as well as user profiles. As the inclusion of features allowing for social interaction has become so common in gamification strategies (Hamari \& Koivisto, 2015), they are sometimes treated as regular game elements. However, if those are the only "game" elements included, does the system then count as being gamified? Tending towards the pole of a constrained categorization of game elements in the 
context of public participation, we saw relevance in distinguishing those projects from "true" game-based or gamification approaches and hence coined the term social participation forums. Nine projects were categorized under this label, of which the vast majority - true to their name implements a Discuss type of engagement. While the incorporated features certainly allow for a two-way communication form, the institutions operating the platform do not always use them and leave the discussing entirely to the citizens. Examples for this include Betri Reykjavik (Citiziens Foundation, n.d.), Bürgerhaushalt Lichtenberg (n.d.) and weLoveOttakring (n.d.). Further illustrative for this type is Activism (n.d.), which directly links to a social networking site by using Facebook's commenting function.

Other platforms that incorporated just one game element were labeled as competitive participation tools. Here the concept is to arrange for competition among users in order to find solutions to various topics. Citizens, either local or from basically anywhere, can submit their ideas and by doing so are involved in decision-making. The responding game mechanics are competition and challenge. In our sample we found two competitive participation tools: Next Stop Design (Brabham, 2009) and Stadtmacher (2015). As for type of engagement, both examples could be categorized as either Ask or DIY. On the one hand an institution - in the case of Next Stop Design the public transport organization together with the adjacent university - is asking the public for input on a specific issue (in this case: how to design the bus stop). On the other hand, if accepting one specific proposal, the solution would have come from the public. Either way, in the reviewed examples, the communication form was restricted to one-way and limited two-way, as no interaction between the stakeholders took place during the competition phase.

\subsubsection{Platforms Employing Gamification}

Although a great portion of e-Participation projects can be classified as game-related, only eight platforms fall under the category of applying gamification. This confirms our a priori beliefs and hypotheses that this niche is quite underexplored. In order to provide an overview of current strategies for gamified participation that also makes it possible to identify gaps, we combined selected categories of participation related and game related aspects in a matrix. Following our objective to provide a concise and thus comprehensible overview, we selected only those dimensions that distinguish the individual gamification projects. For instance the dimension "involved stakeholders" was not selected, as all eight platforms involve at least two different stakeholders. With both "type of engagement" and "data collection" describing related aspects but the latter comprising more information, we decided on "data collection". Furthermore, with responsiveness being a central factor in determining the intention of a participation platform (Aichholzer \& Westholm, 2009; Harding et al., 2015; Lee \& Kwak, 2012), the implemented "communication form" was found to also be an important aspect when describing the current state of the art of gamified participation tools. Regarding the game-related aspects, we decided to omit "game platform" as all identified gamification projects used technology and therefore classified as video-game or when having a location-based component as pervasive game. We also opted to not distinguish between "game genres". Because gamified applications focused on the serious, main aspect of a system, a distinction between genres was often ambiguous. A possibility would have been to include a categorization of different gamification strategies (e.g., reward-based and 
meaningful; Nicholson, 2013). However, using only eight platforms to categorize a matrix with three axes consisting of multiple variables would have made the overview too complex and convoluted. The dimension "game type" is inherently included in the matrix as the selection of its category gamification is a pre-condition for this overview. This left us with two dimensions forming the two axes of the matrix, "data collection" and "communication form". The eight identified gamification projects were then sorted into the matrix (see Fehler! Verweisquelle konnte nicht gefunden werden.). Revisiting the limitations of our methodology for this review in respect to limited sources and restricted access to applications that we could test, some projects might not be categorized in the appropriate box. Those projects, where we cannot guarantee a correct categorization precisely due to these restrictions, are marked with a star.

Figure 1: Matrix of e-Participation Platforms Applying Gamification ${ }^{1}$.

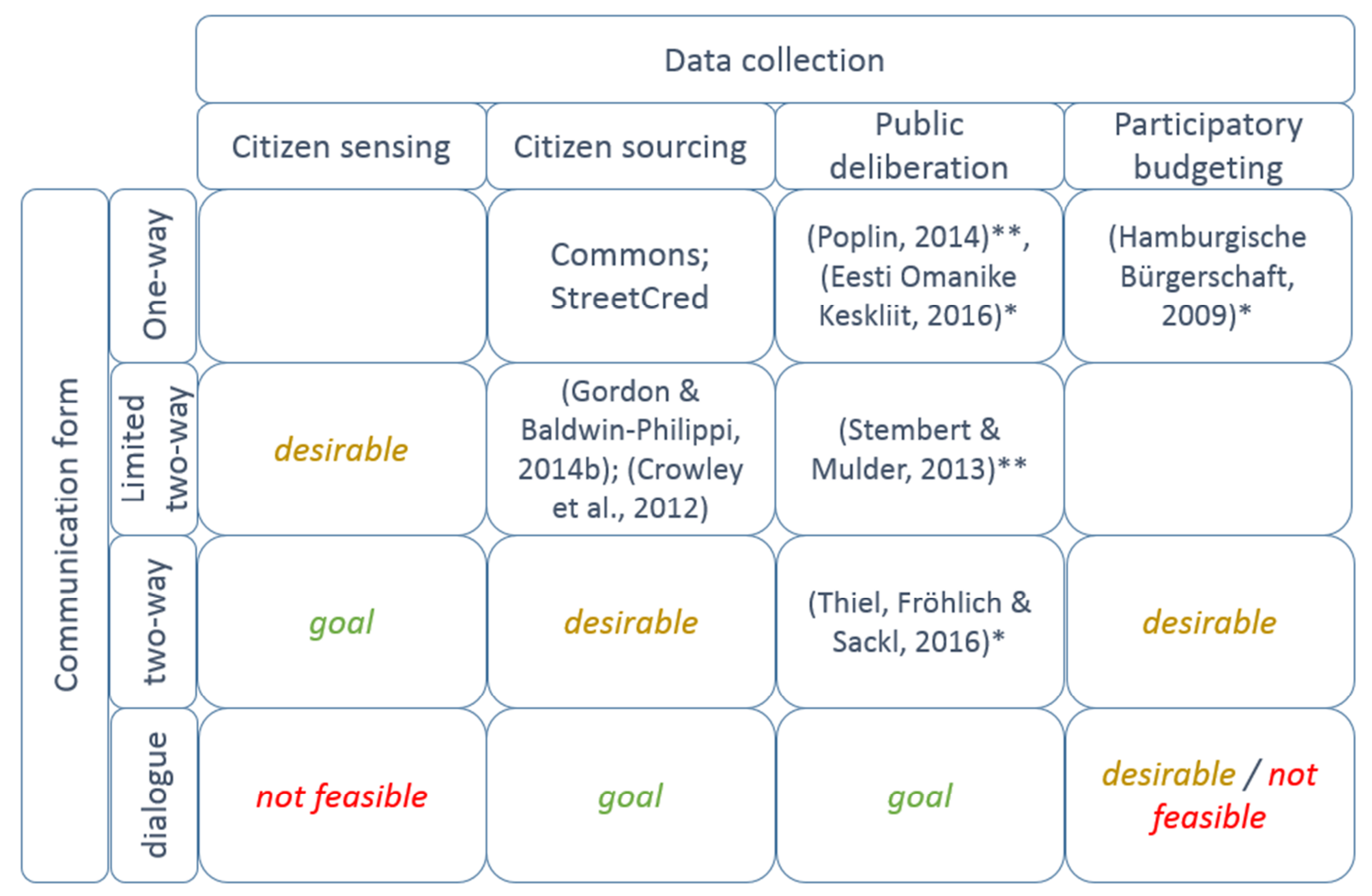

The clear majority of gamified participation projects employ citizen-sourcing and public deliberation approaches as an instrument to involve the public. Again, the difference between those two categories is that in public deliberation, citizens can introduce their own topics rather than responding to a call from authorities that correspond to a specific topic. With one exception, none of the projects achieves a two-way interaction with the administering institution and within those parts of the participatory process that is represented in the platform. Some of the gamified

1 Classification based on reports and publically available information, except ${ }^{*}$ which were tested. In ${ }^{* *}$ the development of the prototype was the main goal. 
citizen-sourcing platforms in our sample do however give rudimental feedback in the form of status updates (e.g., a field indicating whether the request has been processed yet).

All four examples of gamified "citizen-sourcing" work with points and badges, suggesting that they follow a reward-based gamification approach (Nicholson, 2013). The web-based deliberation platform B3-Design your marketplace is the only exception here. With B3 providing space for playful-exploration but lacking a clear structure and visible outcomes of the participation process, the authors have noted that it was sometimes difficult to tell the difference between pure play and a serious contribution (Poplin, 2014). Those projects with a limited two-way communication also incorporated social aspects such as social interaction and social recognition. Considering that these platforms include a fair amount of game-related components including leaderboards and levels, it can be said that their gamification strategy is rather complex. This lets the gamefulness appear rather prominent. A risk with this approach is that those people who are alienated by systems or methods that resemble games might be turned off by the design. A popular claim of those people resenting anything game-like is that they do not have time to "play around" and that games are meant for children (see Marczweski, 2016 for a discussion on this). Moreover, basing a gamification strategy solely on achievement systems that seek for competition as a driving force to motivate users to engage, is fraught with risks as well. Several empirical studies have reported negative effects when working with components that induce competition (Eveleigh et al., 2013; Preist, Massung, \& Coyle, 2014). We argue that the same applies when employing such gamification strategies in the respective public deliberation examples.

While our sample did include some "citizen-sensing" applications, none of them incorporated any elements typical for games. In this approach, it is not citizens who compose content such as ideas or complaints, but sensors that are usually integral to smartphones (e.g., camera, accelerometer) which collect specific types of data (e.g., air pollution). This data is then automatically sent to authorities. In most cases users cannot interfere with this procedure and cannot modify or augment the data that is being sent. Although the data is used to inform policies and decisions, citizens are not actively involved. Consequently, despite being a form of public participation, from the citizens' perspective, citizen-sensing is not a desirable option. Gamification is an approach that aims to increase motivation as well as influence usage behavior. As users' options for interacting within citizen-sensing applications are limited, employing a strategy to influence usage patterns does not seem very convenient. Nevertheless, applying gamification to this engagement form might make more people curious and willing to test the application. Considering that some citizensensing initiatives only run for a limited time (i.e., until enough data is collected), applying gamification to support onboarding might be sufficient support to achieve the participation goals (i.e., number of people submitting samples).

Another sparsely populated category is the gamification of participatory budgeting. The only project in that area that we identified as game-related does not conform to typical gamification approaches. In fact, Hamburger Haushalt (Hamburgische Bürgerschaft, 2009) only incorporates elements that are characteristic but not unique to games (Deterding et al., 2011), namely profile and scarcity. The latter applies as certain calls for citizens' input were time-limited. Moreover, the 
platform itself - not the administering institution - gave feedback in a sense that it provided information about the implications of suggested changes to the current budgeting.

Switching to the axis pertaining the communication form, Figure 1 shows another gap in possible gamified participation approaches: achieving a dialogue between two stakeholders. Technology-wise such a civic dialogue is already possible (e.g., via instant messaging). Although a timely and delay-free interaction between a city and its citizens is certainly desirable, it is hardly feasible considering the way local administrations are organized at the moment. Shorter time spans between citizens' requests and official responses would require more resources as well as clearly assigned and communicated responsibilities within the various city departments. A study investigating the responsiveness of city officials in the UK has shown that currently citizens have to wait up to two working days for a response (Kearns et al., 2002). While this is arguably not long, it can hardly be called a real-time, interactive conversation. In order to fulfill the basic criteria for effective and sustainable participation that further have the potential to increase civic trust, future participation platforms should in general aim for two-way communication. It is noteworthy, that the design of a platform does not always determine the communication form achieved in a participatory process. While a great amount of reviewed applications included features that would have allowed for a two-way communication, they were not used by the administrating institution.

\section{Discussion}

Gamification describes the usage of game elements in non-game contexts (Deterding et al., 2011). With the great variety of game elements, aesthetics and mechanics, there is a plethora of different gamification approaches. This can be considered a positive circumstance, as it has pointed out that one size (i.e., one gamification strategy) does not fit all [contexts] (Devisch et al., 2016). With that said, this review has shown that the majority of gamification approaches focus on reward-based elements (i.e., points, levels, badges). While this strategy might lead to the desired outcomes in some cases, it also holds the risk of replacing intrinsic with extrinsic motivation (so-called crowding-out effect; Osterloh \& Frey, 2002).

In our gamified participation review matrix, we further identified opportunity spaces for future e-Participation applications. These spaces were rated using a traffic light metaphor ranging from "goal" = green, "desirable" = orange to "not feasible" = red. Overall, spaces were rated as more favorable the higher they scored on the "communication form" axis (i.e., using Arnstein's (1969) ladder of participation as analogy). While dialogue is desireable, it might not always be feasible or fit into the point of action depending on the context. We thus identified two exceptions to this rule: Citizen sensing and participatory budgeting both yield themselves ill to dialogue (i.e., delay-free conversation). Citizen sensing builds on the idea that data is automatically collected through sensors and sent directly to the respective authority, where the data is analyzed. Usually citizens have no way to interact with the sensory data - having a conversation regarding this data is thus only possible after the data has been processed. A dialogue could be organized after this process, considering for instance what results were gained from the data (e.g., fixing a particular road due to too many recognized bumps). Such a dialogue would then fall under another "data collection" type (e.g., public deliberation). A similar constraint applies to dialogues in participatory budgeting. 
Concerning ideas on the allocation of budget, it makes sense to run calculations based on suggestions from citizens before providing feedback on them. In contrast, the only constraint to the realization of dialogues in citizen sourcing and public participation are the limited resources of city administration and their often complex vertical hierarchy of responsibilities. To really involve citizens, empowering them to be part of decision-making processes instead of pretending that they are being heard by providing meaningless status messages is essential, which requires an ongoing feedback loop. Thus, e-Participation platforms should provide a two-way communication channel in these contexts. Making the participation experience gameful and maybe even fun is surely no replacement for assuring citizens of their level of influence.

Another aspect that became apparent in course of this review is that just because a platform uses elements that are characteristic of games does not necessarily make it a gamified. In order to leverage the affordances of gameful design, one does not have to turn to stereotypical elements such as points and leaderboards, but could implement a more subtle approach inspired by games. Such an approach might include the integration of less common game elements like narratives. Story-telling has been found to be able to provide a meaningful frame that helps citizens understand how various topics relate to them and why they should care (Walz \& Deterding, 2015). Employing subtle gamification might also diminish the risk of alienating those less affine or even opposed to games. Consequently, e-Participation platforms following those guidelines might cast a wider net (i.e., evoke curiosity in youth and gamers) and at the same time avoid discouraging others.

Social participation forums operate on related principles: There is certainly no doubt that social networking sites have been widely adopted by the population (Höffken \& Haller, 2010). Instead of trying to re-invent the wheel, this type of e-Participation platform makes use of existing concepts for social interaction which are characteristic to social media. This strategy comes with the benefit of using technologies that most people are already familiar with and hence do not have to learn. In fact, many discussions regarding current local and international issues take place online via Twitter and Facebook (McAleer, 2016). On the other hand, social networks such as Facebook and Twitter have been said to have a limited ability to engage people as well as to determine how much people really care about an issue (McHarg, 2015). Reflecting on the limited obligation and sometimes seriousness, McHarg described social networks in the context of public participation as "just flinging likes and retweets into the ether" (2015, Productive Actions, para. 2). It still needs to be explored if the approach of going where citizens already are proves to be an efficient and effective way of fostering public participation. After all, conversations taking place in social media cannot always be described as being objective and there is little to no indication of what is a proven fact or trustworthy information. Moreover, making sense of discussions in such a difficult-to-follow format makes it even more cumbersome to draw conclusions and insights for decision-making.

\section{Conclusion}

In this paper we described the methodology of an extensive review process and presented trends regarding the use of game elements in e-Participation platforms. While our sample for this review might not have included all e-Participation systems that exist, having reviewed projects from four 
continents (i.e., America, Europe, Asia and Oceania), we are confident that our selection provides a detailed snapshot of current trends in game-related e-Participation projects.

The presented results showed that using games for civic learning purposes is a quite common strategy to make the public aware of both the complexities and challenges of governance and prepare them for future participatory processes. Yet, gamification has not found wide application in the quest to foster engagement and initiatives applying gamification rely on reward-based gamification. Although the effects of these approaches are yet largely unexplored - particularly so in the context of public participation - previous research leads us to assume that working with points and badges will not result in a sustainable increase in participation. Instead, we suggest the use of either social gamification or more subtle ways of benefitting by the affordances of games. This could translate to introducing mechanisms that support engagement by, for instance, providing additional meaning or rewarding implemented suggestions.

While this is a first step towards an overview of gamified participation strategies and its possibilities, the material resulting from this review offers even more insights by providing ample opportunities to explore this domain from a variety of perspectives and disciplines. With this paper concentrating on the gamification approach, future work will focus on civic games and an analysis of how the factor location is used in participation platforms.

\section{References}

Abt, C.: Serious Games. The Viking Press, New York (1970)

Activism (n.d.). Retrieved September 2016, from http://www.activism.com/de_AT/petitiononline.at

Arnstein, S. R. (1969). A ladder of citizen participation. Journal of the American Institute of planners, 35(4), 216-224.

Åström, J., \& Grönlund, ̊̊. (2012). Online Consultations in Local Government: What Works, When, and Why. In Coleman, S., \& Shane, P. (eds.) Connecting democracy: Online consultation and the flow of political communication, MIT-Press

Aichholzer, G., \& Westholm, H. (2009). Evaluating eParticipation projects: practical examples and outline of an evaluation framework. European Journal of ePractice, 7(3), 1-18.

Brabham, D. C. (2009). Next Stop Design. Retrieved September 2016, from http:/ / first.nextstopdesign.com/

Brady, H. E., Verba, S., \& Schlozman, K. L. (1995). Beyond SES: A resource model of political participation. American Political Science Review, 89(02), 271-294.

Brown, G. G., \& Pullar, D. V. (2012). An evaluation of the use of points versus polygons in public participation geographic information systems using quasi-experimental design and Monte Carlo simulation. International Journal of Geographical Information Science, 26(2), 231-246.

Bohøj, M., Borchorst, N. G., Bødker, S., Korn, M., \& Zander, P. (2011). Public deliberation in municipal planning: Supporting Action and Reflection with Mobile Technology. Proceedings of the 5th International Conference on Communities and Technologies - C\&T '11, (July), 88. 
Bowser, A., Hansen, D., Preece, J., He, Y., Boston, C., \& Hammock, J. (2014). Gamifying citizen science: a study of two user groups. In Proceedings of the companion publication of the 17th ACM conference on Computer supported cooperative work \& social computing (pp. 137-140). ACM.

Brucher, H., \& Baumberger, P. (2003). Using mobile technology to support eDemocracy. In System Sciences, 2003. Proceedings of the 36th Annual Hawaii International Conference on (pp. 8-pp). IEEE.

Bürgerhaushalt Lichtenberg (n.d.) Retrieved September 2016, from https://www.buergerhaushaltlichtenberg.de/

Burke, J., Estrin, D., Hansen, M., Parker, A., Ramanathan, N., Reddy, S., Srivastava, M. B. (2006). Participatory Sensing. World Sensor Web Workshop.

Caddy, J., \& Vergez, C. (2001). Citizens as partners: Information, consultation and public participation in policy-making. OECD Online Bookshop.

Chakraborty, A. (2011). Enhancing the role of participatory scenario planning processes: Lessons from Reality Check exercises. Futures, 43(4), 387-399.

Chou, Y-K. (2015). “Actionable Gamification: Beyond Points, Badges, and Leaderboards". CreateSpace.

Citiziens Foundation (n.d.) Retrieved September 2016, from Betri Reykjavik: https:/ /www.betrireykjavik.is /

Clearwater, D. (2011). What defines video game genre? Thinking about genre study after the great divide. Loading..., 5(8).

Cohn, J. (2008). Citizen science: Can volunteers do real research? BioScience, 58, 3 (2008), 192-107.

Commons (2016). Retrieved September 2016, from Commons: http:/ / civictripod.com/games/commons/

Crowley, D. N., Breslin, J. G., Corcoran, P., \& Young, K. (2012). Gamification of citizen sensing through mobile social reporting. In IEEE International Games Innovation Conference (IGIC), (pp. 1-5). IEEE.

Deterding, S., Dixon, D., Khaled, R., Nacke, L., Sicart, M., \& O'Hara, K. (2011). Gamification: Using Game Design Elements in Non-Game Contexts. In Proceedings of the 2011 Annual Conference Extended Abstracts on Human Factors in Computing Systems (pp. 2425-2428).

Devisch, O. (2008). Should planners start playing computer games? Arguments from SimCity and Second Life. Planning Theory \& Practice, 9(2), 209-226.

Devisch, O., Poplin, A., \& Sofronie, S. (2016). The Gamification of Civic Participation: Two Experiments in Improving the Skills of Citizens to Reflect Collectively on Spatial Issues. Journal of Urban Technology, $1-22$.

Digital Democracy Commission. (2015). Report of the Speaker's Commission on Digital Democracy. Available online at http:/ / www.digitaldemocracy.parliament.uk/documents/Open-Up-DigitalDemocracy-Report.pdf.

Duke, R. D. (2011). Origin and evolution of policy simulation: A personal journey. Simulation \& Gaming, 20(10), SAGE Publications.

Eesti Omanike Keskliit. (2016). Retrieved September 2016, from Petitsioon.ee: http:/ / petitsioon.ee/ 
Eickhoff, C., Harris, C. G., de Vries, A. P., \& Srinivasan, P. (2012). Quality through flow and immersion: gamifying crowdsourced relevance assessments. In Proceedings of the 35th international ACM SIGIR conference on Research and development in information retrieval (pp. 871-880). ACM.

Ertiö, T. (2013). M-participation : the emergence of participatory planning applications. Research Briefings. Retrieved from www.turku.fi/kaupunkitutkimus/julkaisut/

Eveleigh, A., Jennett, C., Lynn, S., \& Cox, A. L. (2013). “I want to be a captain! I want to be a captain!”: gamification in the old weather citizen science project. Proceedings of the First International Conference on Gameful Design, Research, and Applications - Gamification '13, 79-82.

Flanagan, M. (2009). Critical play: radical game design. Cambridge, Mass: MIT Press.

George, G. \& Camarata, M. (1996). Managing instructor cyberanxiety: The role of self-efficacy in decreasing resistance to change. Educational Technology, 36(4), 49-54.

Glenn, E. H. (2012). Playing Games with the Budget: Ideas for Emphasizing the Legislative Elements of Budget-Making Through an Online Multiplayer Toy. Available at SSRN 2171435.

Gordon, E., Michelson, B., \& Haas, J. (2016). @ Stake: A Game to Facilitate the Process of Deliberative Democracy. In Proceedings of the 19th ACM Conference on Computer Supported Cooperative Work and Social Computing Companion (pp. 269-272). ACM.

Gordon, E., \& Baldwin-Philippi, J. (2014a). Playful civic learning: Enabling lateral trust and reflection in game-based public participation. International Journal of Communication, 8, 28.

Gordon, E., \& Baldwin-Philippi, J. (2014b). Civic Learning Through Civic Gaming: Community PlanIt and the development of trust and reflective participation. International Journal of Communication, 8, 759786.

Hamari, J., \& Koivisto, J. (2013). Social motivations to use gamification: an empirical study of gamifying exercise. In Proceedings of the 21st European Conference on Information Systems, Utrecht, Netherlands.

Hamari, J., \& Koivisto, J. (2015). Why do people use gamification services?. International Journal of Information Management, 35(4), 419-431.

Hamari, J., \& Koivisto, J. (2015). “Working out for likes": An empirical study on social influence in exercise gamification. Computers in Human Behavior, 50, 333-347. http://doi.org/10.1016/j.chb.2015.04.018

Hamari, J., Koivisto, J., \& Sarsa, H. (2014). Does gamification work? - A literature review of empirical studies on gamification. Proceedings of the Annual Hawaii International Conference on System Sciences, 30253034 .

Hamburgische Bürgerschaft. (2009). Retrieved September 2016, from Bürger Haushalt 2009: http://www.buergerhaushalt-hamburg.de/

Harding, M., Knowles, B., Davies, N., \& Rouncefield, M. (2015). HCI, Civic Engagement \& Trust. In Proceedings of the 33rd Annual ACM Conference on Human Factors in Computing Systems (pp. 2833-2842). ACM. 
Hunicke, R., LeBlanc, M. \& Zubek, R. (2014). MDA: A formal approach to game design and game research. In Proceedings of the AAAI Workshop on Challenges in Game AI (pp. 4-16).

Ipeirotis, P. G., \& Gabrilovich, E. (2014). Quizz: targeted crowdsourcing with a billion (potential) users. In Proceedings of the 23rd international conference on World wide web (pp. 143-154). ACM.

Itoko, T., Arita, S., Kobayashi, M., \& Takagi, H. (2014). Involving senior workers in crowdsourced proofreading. In International Conference on Universal Access in Human-Computer Interaction (pp. 106-117). Springer International Publishing.

John, P., Smith, G., \& Stoker, G. (2009). Nudge nudge, think think: two strategies for changing civic behaviour. The Political Quarterly, 80(3), 361-370.

Kawajiri, R., Shimosaka, M., \& Kashima, H. (2014). Steered crowdsensing: Incentive design towards qualityoriented place-centric crowdsensing. In Proceedings of the 2014 ACM International Joint Conference on Pervasive and Ubiquitous Computing (pp. 691-701). ACM.

Kearns, I., Bend, J., Brooke, Lord, Edmonds, J., Humphries, J., \& Sweeney, E. (2002). E-participation in Local Government. London, UK: Institute for Public Policy Research.

Laureyssens, T., Tanguy Coenen, L. C., \& Mechant, R., Criel, J. (2014). ZWERM: a Modular Component Network Approach for an Urban Participation Game. In CHI (pp. 3259-3268).

Lee, G., \& Kwak, Y. H. (2012). An Open Government Maturity Model for social media-based public engagement. Government Information Quarterly, 29(4), 492-503.

Lee, T. Y., Dugan, C., Geyer, W., Ratchford, T., Rasmussen, J. C., Shami, N. S., \& Lupushor, S. (2013). Experiments on Motivational Feedback for Crowdsourced Workers. In ICWSM.

Lerner, J. A. (2014). Making democracy fun: How game design can empower citizens and transform politics. MIT Press.

Macintosh, A. (2004). 'Using information and communication technologies to enhance citizen engagement in the policy process' in Promises and Problems of E-Democracy: Challenges of online citizen engagement. Paris: OECD. ISBN 92-64-01948-0. Available at: http://www1.oecd.org/publications/ebook/4204011E.PDF

Macintosh, A. (2004a). Characterizing e-Participation in policymaking. Proceedings of the 37th Annual Hawaii International Conference on System Sciences.

Marczweski, A. (2016, September 20). I'm too Busy and Important to Play Games. Retrieved from Gamified UK: https://www.gamified.uk/2016/09/20/im-busy-important-play-games /

Mayer, I. S. (2009). The Gaming of Policy and the Politics of Gaming: A Review. Simulation \& Gaming, 40(6), $825-862$.

McAleer, S. R., Panopoulou, E., Glidden, J., Tambouris, E., \& Tarabanis, K. (2016). Augmenting Social Talk: The \# ask Project. In Conference for E-Democracy and Open Government (pp. 61-67).

McHarg, S. (2015). Engaging Citizens: A Review of Eight Approaches to Civic Engagement. User Experience Magazine, 15(5). Retrieved from http:/ / uxmagazine.org/engaging-citizens/ 
Michael, D. R., \& Chen, S. L. (2005). Serious games: Games that educate, train, and inform. Muska \& Lipman/Premier-Trade.

Morschheuser, B., Hamari, J., \& Koivisto, J. (2016). Gamification in crowdsourcing: a review. In 49th Hawaii International Conference on System Sciences (HICSS) (pp. 4375-4384). IEEE.

Nam, T. (2011). Suggesting frameworks of citizen-sourcing via Government 2.0. Government Information Quarterly (29), 12-20.

Newman, J. (2004). Videogames. New York: Routledge.

Nicholson, S. (2012). A user-centered theoretical framework for meaningful gamification. Games+ Learning+ Society, 8,1 .

Nicholson, S. (2013). Two paths to motivation through game design elements: Reward-based gamification and meaningful gamification. In Proceedings of the iConference 2013 (pp. 671-672).

OECD (2001) Engaging Citizens in Policy making: Information, Consultation and Public Participation. Available at http://www.oecd.org/dataoecd/24/34/2384040.pdf

Osterloh, M., Frost, J., \& Frey, B. S. (2002). The dynamics of motivation in new organizational forms. International Journal of the Economics of Business, 9(1), 61-77.

Pahad, E. (2005). Political Participation and Civic Engagement. Progressive Politics, 4(2), pp. 21-26.

Parent, M., Vandebeek, C. A., \& Gemino, A. C. (2005). Building citizen trust through e-government. Government Information Quarterly, 22(4), 720-736.

Poplin, A. (2014). Digital serious game for urban planning: “B3-Design your Marketplace!” Environment and Planning B: Planning and Design, 41(3), 493-511.

Preist, C., Massung, E., \& Coyle, D. (2014). Competing or aiming to be average?: normification as a means of engaging digital volunteers. Proceedings of the 17th ACM Conference on Computer Supported Cooperative Work \& Social Computing - CSCW '14, 1222-1233.

Reddy, S., Samanta, V., Burke, J., Estrin, D., Hansen, M., \& Srivastava, M. (2009). MobiSense-mobile network services for coordinated Participatory Sensing. In Proccedings of International Symposium on Autonomous Decentralized Systems. (pp. 1-6). IEEE.

Rowe, G. \& Gammack, J. G. (2004). Electronic engagement. Promise and perils of electronic public engagement, Science and Public Policy 31(1), 39-54.

Rowe, G., \& Frewer, L. J. (2005). A Typology of Public Engagement Mechanism. Science, Technology, \& Human Values, 30(2), 251-290.

Rucker, D. (2015, March 11). Four Types of Public Engagement: Tell, Ask, Discuss, Decide. Retrieved from Creating a Wise Economy : https://medium.com/creating-a-wise-economy/four-types-of-publicengagement-tell-ask-discuss-decide-e58a22d42336\#.qwrdsvob2

Ryan, R. M., \& Deci, E. L. (2000). Self-determination theory and the facilitation of intrinsic motivation, social development, and well-being. American psychologist, 55(1), 68.

Stadtmacher (2015). Retrieved September 2016, from https:/ / www.stadtmacher.org/ 
Stembert, N., \& Mulder, I. J. (2012). Love your city! An interactive platform empowering citizens to turn the public domain into a participatory domain. In Proceedings of International Conference Using ICT, Social Media and Mobile Technologies to Foster Self-Organisation in Urban and Neighbourhood Governance.

StreetCred (2016). Retrieved September 2016, from StreetCred: http:/ / streetcred.us/

Sust. (n.d.). My Sust House. Retrieved September 2016, from http://mysusthouse.org/game.html

Tambouris E., Liotas N., Tarabanis K. (2007). A Framework for Assessing eParticipation Projects and Tools. In Proceedings of the 40th Annual Hawaii International Conference on System Sciences (HICSS '07).

Taylor, J. (1971). Instructional planning systems: A gaming-simulation approach to urban. Cambridge, UK: Cambridge University Press.

Thiel, S.-K. (2016a). Reward-based vs. Social Gamification: Exploring Effectiveness of Gamefulness in Public Participation. In Proceedings of the 9th Nordic Conference on Human-Computer Interaction (forthcoming). Göteborg, Sweden.

Thiel, S. K. (2016b). A Review of Introducing Game Elements to e-Participation. In Proceedings of CeDEM16: Conference for E-Democracy and Open Government (pp. 3-9). IEEE.

Thiel, S-K., Fröhlich, P. \& Sackl, A. (2016). Experiences from a Living Lab Trialing a Mobile Participation Platform. In Proceedings of Real Corp '16: 21st International Conference on Urban Planning and Regional Development in the Information Society GeoMultimedia 2016 (pp. 263-272). Hamburg, Germany.

Thiel, S-K. \& Poikela, M. (2015). What Do I Get Out Of It? Reflection on the Use of Incentives for Civic Engagement. In Proceedings of Ethical Encounters in HCI, a OzCHI '2015 workshop. Available at https:/ / ethicalencountershci.wordpress.com/ozchi-2015-workshop/ozchi-position-papers.

Thomas, J. C., Streib, G. (2003). The new face of government: citizen-initiated contact in the era of egovernment. Journal of Public Administration Research and Theory, 13(1), 83-102.

Torres, L. H. (2007). Citizen sourcing in the public interest. Knowledge Management for Development Journal, 3(1), 134-145.

Tóth, E., Poplin, A. (2014). ParticiPécs - a cooperative game fostering learning about the built environment and urban planning. In Proceedings of the 17th AGILE Conference on Geographic Information Science.

Toots, M., Kalvet, T., \& Krimmer, R. (2016). Success in eVoting-Success in eDemocracy? The Estonian Paradox. The Estonian Paradox. In Proceedings of the 8th IFIP WG 8.5 International Conference (pp. 5566). Guimarães, Portugal,

Ueyama, Y., Tamai, M., Arakawa, Y., \& Yasumoto, K. (2014). Gamification-based incentive mechanism for participatory sensing. In Proceedings of IEEE International Conference on Pervasive Computing and Communications Workshops (pp. 98-103). IEEE.

United Nations. (2014). E-Government Survey: E-Government For The Future We Want. Accessible online: https://publicadministration.un.org/egovkb/Reports/UN-E-Government-Survey-2014

Van der Heijden, H. (2004). User acceptance of hedonic information systems. MIS quarterly, 28(4), 695-704. 
Van Deursen, A. \& J. van Dijk, J. (2013). The digital divide shifts to differences in usage. New Media \& Society, $16(3), 507-526$.

Vigoda, E. (2002). From responsiveness to collaboration: Governance, citizens, and the next generation of public administration. Public Administration Review, 62(5), 527-540.

Walz, S. P., \& Deterding, S. (2015). The gameful world: Approaches, issues, applications. MIT Press.

We Love Ottakring (n.d.). Retrieved September 2016, from http://www.weloveottakring.at/

Wolf, M.J. (2001). The medium of the video game. Austin: University of Texas Press.

Zichermann, G., \& Cunningham, C. (2011). Gamification by design: Implementing game mechanics in web and mobile apps. O'Reilly Media, Inc.

\begin{abstract}
About the Authors
Sarah-Kristin Thiel

Sarah-Kristin Thiel works as a junior scientist at the AIT Austrian Institute of Technology, Vienna and is pursuing a PhD from the University of Salzburg. In her thesis, she investigates the influences of gameinspired elements in public participation platforms. She received a Master's degree in media informatics from Ludwig-Maximilians University in Munich, Germany. Her research interests include (mobile) humancomputer interaction, interaction design and technology in society. She is currently involved in two EUprojects dealing with e-Participation.
\end{abstract}

\title{
Michaela Reisinger
}

Michaela Reisinger is a junior scientist at AIT Austrian Institute of Technology, Vienna. She has a strong international and interdisciplinary research background concerning individual and societal identity, makeup and change from an osteology/human ethology perspective. Her research currently focuses on user experience in the context of smart cities, emotions in (smart) homes and workplaces, as well as social engineering vulnerabilities in company environments.

\section{Kathrin Röderer}

Kathrin Röderer is a scientist at AIT who has many years of experience in investigating the influence of the (technical) environment on human perception and behavior. Her PhD research in environmental psychology (University of Vienna) focused on the beneficial effects of nature on human well-being. She is an expert in deriving user insights based on a wide range of quantitative and qualitative empirical research methods. Her current scientific interest lies in behavior change through persuasive technologies in different contexts, such as energy consumption, sustainable mobility behavior, and smart workplaces.

\section{Peter Fröhlich}

Dr. Peter Fröhlich, is a Senior Scientist at the AIT Austrian Institute of Technology, where he leads a team of researchers working on ubiquitous and mobile experience. His research interests include contextual interfaces, pervasive interaction, participatory interaction, as well as persuasive technologies for sustainable and privacy-aware behavior. Peter holds a master's degree in Psychology (2001) and a PhD in Applied Psychology (2007). He has authored more than 70 peer-reviewed scientific papers, and he is a regular organizer, editor and reviewer for conferences and journals (J. Personal and Ubiquitous Computing, Mobile $\mathrm{HCl}$ and $\mathrm{CHI}$ ), co-organizing the International Workshop Series on Pervasive Participation, held in conjunction with the C\&T 2013, the Ubicomp 2015 and the NordiCHI 2016 conferences. 